\title{
Los principios de las políticas educativas en Japón sobre la atención a los estudiantes con raíces en el extranjero: una comparación con las políticas educativas sobre inmigrantes de Australia y Francia
}

\author{
DEREK KENJI PINILLOS MATSUDA*
}

Universidad Sofía, Tokio - Japón

Recibido el 04-12-2016; primera evaluación el 31-07-2017; segunda evaluación el 13-11-2017; tercera evaluación el 15-12-2017; aceptado el 27-02-2018

\section{RESUMEN}

Este artículo examinó la situación actual y pasada de los hijos de extranjeros insertos en el sistema educativo japonés. Hasta ahora, Japón no tiene una idea concreta en sus políticas y es por eso que se puede afirmar que este sistema presenta algunas deficiencias/problemas que pueden ser mejorados. Con el objetivo de ver cómo los principios de las políticas nacionales afectan a la educación, en este artículo se han presentado los ejemplos de Australia, como una nación llevando los principios del multiculturalismo y a Francia, como ejemplo de una nación llevando los principios del republicanismo y sus políticas para la integración de sus ciudadanos. La literatura utilizada en este trabajo incluye las políticas y documentos críticos escritos por expertos, los cuales fueron de gran ayuda para poder analizar los pros y contras de las políticas de los distintos países estudiados. Como resultado, el gobierno japonés va a necesitar una política concreta para apoyar a los estudiantes extranjeros a adaptarse a la sociedad y convertirse en un recurso humano productivo para mejorar el país.

Palabras clave: multiculturalismo, republicanismo, sistema educativo.

Profesional con estudios de pregrado de Política General en la Universidad Kwansei Gakuin, Hyogo. Realizó sus estudios de maestría en Educación en la Universidad Sofia, Tokio. Finalmente, cuenta con estudios de doctorado en Educación en la misma universidad. Contacto: dkpm9488@gmail.com 
The doctrine of the educational policies for foreign students in Japan: A comparison between Australian and French educational policies for children of immigrants

\section{Abstract}

In this article, readers are going to see how foreigners' children have been treated in the Japanese educational system. Until now, Japan does not have a specific principle idea in their policies; therefore, those are not stable and concrete. In order to investigate how national policies and its doctrine are important in the educational system, this article has examined Australia as a nation introducing the principles of multiculturalism and France as a nation introducing the republicanism in their integrated politics by doing a literature research. The literature that was used in this paper include the policies and critical papers written by experts that has allow us to analyze the pros and cons of their policies. As a result, the Japanese government is urged to create a concrete policy that would support foreign students to better adapt to the society and become a productive human resource to improve the country's wellbeing.

Keywords: multiculturalism, republicanism, educational system.

Os princípios das políticas educativas no Japáo de apoio aos estudantes estrangeiros: Uma comparaçáo com as políticas educativas sobre imigrantes de Austrália e França

\section{RESUMO}

Neste artigo, pode-se verificar como os filhos de estrangeiros têm sido tratados dentro do sistema educacional japonês. Até o momento, o Japão não tem uma política de inclusão bem definida e, consequentemente, seu sistema não está bem estabelecido. Como medida para avaliar a influência dos princípios das políticas nacionais na educaçáo, neste trabalho, foram apresentados exemplos de outros países. Através de uma investigaçáo da literatura, foram estudados os seguintes países, a Austrália, uma naçáo que cultiva os princípios do multiculturalismo, e a França, levando os princípios do republicanismo e suas políticas de integração dos cidadáos. Esta revisão foi baseada nos princípios e nos respectivos documentos analíticos escritos por especialistas com o objetivo de avaliar as vantagens e desvantagens da política de integração desenvolvida nos países anteriormente mencionados. Em vista disso, sugere-se ao governo japonês a adoção de uma política concreta de apoio aos estudantes estrangeiros a fim de facilitar sua adaptação a sociedade, resultando na formação de recurso humano qualificado e produtivo, contribuindo para o desenvolvimento do país.

Palavras-chave: Multiculturalismo, republicanismo, sistema educacional. 


\section{INTRODUCCIÓN}

Estamos en una era en la que las personas, objetos y dinero se mueven constantemente entre países y continentes. Este movimiento, llamado globalización, surge principalmente como consecuencia del desarrollo económico, el cual avanza a una velocidad inalcanzable. A causa de esto, muchos países se encuentran en un proceso de diversificación de la cultura, ya que nuevas lenguas y costumbres se instalan en estos países gracias a la difusión por parte de los inmigrantes. Muchas personas se enfocan en destacar solamente la parte positiva de este fenómeno, sin embargo también es importante mencionar los problemas que han surgido a partir de esta época. Este artículo se centrará en el problema de la educación en estos países que están pasando por un proceso de diversificación.

Debido a la globalización, la educación dentro de los colegios está cambiando constantemente y en muchos casos, siguen los mismos principios que el país está llevando. Por ejemplo, según Bedmar y Terrón (2013), Francia, siendo una nación republicana, no permite ningún tipo de símbolo religioso dentro del colegio como por ejemplo: el rosario de los católicos, el velo que cubre la cabeza y a veces el cuerpo de las mujeres musulmanas, etc. Francia, como una república, tiene que fomentar la unificación en sus ciudadanos. De igual manera las escuelas tienen que uniformizar a sus estudiantes para que no haya conflictos entre religiones y creencias.

El objetivo de este artículo es analizar si la educación japonesa es adecuada o no para todos los niños que viven en dicho país, específicamente para los niños con raíces extranjeras. De esta manera, se verán los ejemplos de Francia y Australia, dos naciones multiculturales que han trabajado particularmente con las políticas educativas para estudiantes con raíces extranjeras. Después de realizar este análisis se intentará evaluar si en realidad la educación de Japón está atendiendo a las necesidades de los niños con raíces extranjeras o no.

En este artículo, se utilizarán exclusivamente las leyes y políticas nacionales, y no las locales para que los resultados sean compatibles. Después de analizar los casos de Australia y Francia, se estudiará el desarrollo en términos educativos de Japón después de la Segunda Guerra Mundial y cómo se encuentra el sistema de educación actualmente. Se considerarán los principios del multiculturalismo y la integración civil como medidas educativas, ya que muchos de estos países están siendo «multiculturalizados» y a su vez buscan las formas para mantener a sus ciudadanos en armonía. Al final del artículo, se demostrará cómo Japón enfrenta el fenómeno de la globalización a través de la educación de los niños con raíces extranjeras. 


\section{LA FORMACIÓN DE LA EDUCACIÓN MULTICULTURAL}

Según García, Pulido y Montes del Castilloé (1997) la educación multicultural nace cuando existe «una presencia de grupos étnicos claramente diferenciados por razones del color de piel, lengua materna, valores y comportamientos religiosos, y, junto a todo ello y otros elementos más, diferencias socioeconómicas, se reconoce la necesidad de una educación 'especial" para atender tales diferencias» (p. 1). La educación multicultural tiene sus raíces en los movimientos de los ciudadanos afrodescendientes en los EE.UU. que surgieron en la década de 1960. A partir de esto, este capítulo examinará primero la historia de la educación multicultural, para luego mostrar la situación en distintos países. Al final de este capítulo se analizarán los problemas actuales de la educación multicultural.

\subsection{Historia}

Gay (1983) analiza y describe el origen de la educación multicultural en tres aspectos. Primero, se pueden ver los movimientos no solo de las personas de raíces africanas sino también, latinas y asiáticas por sus derechos civiles. Segundo, la revisión del programa educativo de refuerzo basado en la teoría de la privación de culturas. Tercero, la exaltación de las críticas a los estereotipos, información errada y la mala representación de los grupos étnicos y razas, puestas en evidencia a través del análisis de los libros escolares.

Debido a estos cambios, la educación multicultural se encuentra en contra de la política asimilacionista en la educación. La política asimilacionista en la educación fue creada para que los grupos étnicos renuncien a sus valores culturales y a su idioma nativo y se adapten a la cultura e idioma del grupo mayor. Este se considera un método tradicional en la educación, en el cual se espera que las minorías étnicas aprendan el idioma y la cultura del grupo dominante para poder llegar a tener éxito en la vida académica.

Después de estos movimientos de grupos étnicos, la educación multicultural se tornó un método de defensa para los grupos minoritarios. Hoy en día la educación multicultural se ha ampliado para incluir también a mujeres, a personas de todas las religiones, de todas las edades, de diferentes capacidades físicas y de diferente orientación sexual. Según la definición de James A. Banks (2006), considerado como el pionero en los estudios de la educación multicultural, "La educación multicultural puede definirse como un campo de estudio o una disciplina cuyo objetivo es crear igualdad de oportunidades para alumnos/as de diferentes grupos raciales, étnicos, socioeconómicos o 
culturales» (s/p) que cubre todos los derechos de todos los alumnos, para que puedan tener la oportunidad de recibir una educación.

La educación multicultural está siendo cada vez más necesitada por aquellas naciones que se están convirtiendo en naciones multiculturales debido al fenómeno de la globalización como mencionamos al principio de este artículo. En el siguiente capítulo se verá el ejemplo de Francia y Australia, dos países multiculturales que tomaron caminos distintos para llegar a donde están hoy en día, mientras Australia tomó los principios de la educación multicultural, Francia siguió con sus principios de «la separación de la iglesia y el estado» (Loi du 9 décembre 1905 concernant la séparation des Eglises et de l'Etat.); fue la ley que el 9 de diciembre de 1905 se estableció y que hasta ahora sigue siendo la ley fundamental en esta nación republicana. Esta ley afectó a muchas otras que se establecieron después, y que en una de ellas se prohíbe la exposición de cualquier tipo de símbolo religioso en un lugar público. Esta ley no solo restringe la libertad de creencia de los ciudadanos, sino también de expresión. Además, se podría decir que esta ley no lleva principios del multiculturalismo y lo único que intenta hacer es unificar a sus ciudadanos. Este capítulo intentará explicar el proceso de cómo estas naciones llegaron a utilizar estas políticas según su historia, para luego intentar descifrar alguna pista que pueda ayudar a Japón a enfrentar este fenómeno con una educación que sea adecuada para todos aquellos niños que viven en este país.

\subsection{Metodología}

Dentro del artículo se verán los ejemplos de Australia y Francia como países multiculturales y se hará una breve comparación de sus políticas para analizar cómo Japón está tratando el fenómeno de la globalización. Después de hacer una comparación de estos países, se analizarán las políticas de Japón para los estudiantes con raíces extranjeras. Lo que se quiere lograr en este estudio es dar luces sobre los principios que Japón está realizando respecto a los inmigrantes, y según los resultados, examinar las posibilidades que tiene este país para tener una educación imparcial.

Todo tipo de información será adquirida por la literatura de estos países analizando sus políticas para inmigrantes. La definición de «inmigrante», en este artículo, se tomará de la siguiente forma: «personas que han nacido en el extranjero», tal como se les define en Australia y Francia. En Japón no se usa con tanta frecuencia la palabra «inmigrante» sino que se usa el término «ciudadanos extranjeros», cuando se quieren referir a los inmigrantes. Cabe resaltar que a diferencia de Australia y Francia, en Japón dentro del término 
«ciudadanos extranjeros» también se incluye a los que han nacido dentro de este país, ya que haber nacido en Japón no significa que las personas obtienen de manera automática la nacionalidad como en muchos otros lugares.

Los principios del multiculturalismo serán tratados basándonos en la definición de Banks (1997), y la integración civil será utilizada con la definición obtenida de la universidad del «Stanford Encyclopedia of Philosophy» (2006).

\section{COMPARACIÓN ENTRE EL MULTICULTURALISMO Y LA INTEGRACIÓN}

\subsection{El multiculturalismo: el ejemplo de Australia}

Según Clair (2011) Australia aplica medidas que responden a un enfoque multicultural. Actualmente, el gobierno está tratando de recibir recursos humanos para el desarrollo del país, y acepta la diversidad de los valores de sus ciudadanos, sobre todo impulsando la inmigración en familia de manera temporal. Sigue los principios del multiculturalismo para atender a sus ciudadanos de orígenes diversos. Según Australian Bureau of Statistics (2016), la estructura demográfica por grupos ciudadanos nacidos fuera de Australia se puede observar en la tabla 1 .

Tabla 1. Ciudadanos nacidos fuera Australia (2016)

\begin{tabular}{lcc}
\hline País de nacimiento & $\begin{array}{c}\text { Número } \\
\text { de personas }\end{array}$ & $\begin{array}{c}\text { Porcentaje de la } \\
\text { población total }\end{array}$ \\
\hline Reino Unido & 1198000 & 5,0 \\
Nueva Zelanda & 607200 & 2,5 \\
China & 526000 & 2,2 \\
India & 468800 & 1,9 \\
Filipinas & 246400 & 1,0 \\
Vietnam & 236700 & 1,0 \\
Italia & 194900 & 0,8 \\
Sudáfrica & 181400 & 0,8 \\
Malasia & 166200 & 0,7 \\
Alemania & 124300 & 0,5 \\
\hline
\end{tabular}


Como se puede ver en la tabla 1, Australia es un país poblado por inmigrantes de diversas partes del mundo, el porcentaje es de $28,5 \%$ de la población total. El multiculturalismo fue introducido en la educación ya que muchas escuelas buscaron recursos para atender a las necesidades de sus alumnos provenientes de diversas culturas e idiomas diferentes. Primero, la educación multicultural fue implementada solo para ayudar a los alumnos cuyo idioma materno no era el inglés. Sin embrago, fueron tantos los alumnos de diferentes idiomas y culturas, que ahora las medidas de educación multicultural son aplicadas para todos los alumnos, incluyendo a los australianos.

Es importante destacar que el multiculturalismo en Australia no solo fue aplicado en la educación, sino que la sociedad en total tuvo un cambio dinámico que comenzó desde la fundación del mismo país.

Australia en sus inicios y luego de la formación del estado federal llevó los principios de "Australia Blanca» (Australian Government, Department of immigration and Border Protection). Esta política fue aplicada a causa del resentimiento de la población anglosajona por la presencia de los asiáticos que trabajaban con un sueldo más bajo que ellos. Estos condujeron a protestas y desórdenes públicos, tanto que en 1888 la inmigración asiática fue excluida de todas las colonias australianas. Los asiáticos y los indígenas fueron discriminados por un largo tiempo dentro de la historia australiana.

En 1958 las leyes de inmigración fueron establecidas. Dentro de estas leyes ningún grupo étnico fue excluido para poder hacer la solicitud de la ciudadanía australiana. Sin embargo, el gobierno australiano introdujo una política de asimilación siguiendo los principios de «Australia Blanca», obligando a todos los inmigrantes a aprender el inglés y la cultura anglosajona, abandonando sus culturas e idiomas nativos. A mediados de los ' 60 el gobierno cambió su política promoviendo la unificación; dejaron de prohibir el aprendizaje de los idiomas y las culturas maternas de los inmigrantes, pero siempre exigiendo hablar el inglés y seguir la cultura de la mayoría. Entrando a la década de 1970, el gobierno de Gough Whitlam suprimió los principios de «Australia Blanca» y comenzó a introducir los principios del multiculturalismo. Justo en esta época, muchas de las personas que quedaron como refugiados de indochina por causa de la guerra de Vietnam entraron a Australia. En 1975, «El Acta de Discriminación Racial de 1975" fue establecida para prohibir toda discriminación por raza, color de piel, nacionalidad y grupos étnicos. Además, en 1978, «Migrant Service and Programs» (Frank Galbally) fue publicado por el gobierno con las siguientes cuatro ideas; 
1. El derecho de mantener las culturas maternas sin prejuicio.

2. Acceso y oportunidades equitativas para que gocen de los servicios públicos.

3. Satisfacer las necesidades de los inmigrantes a través de servicios y programas que puedan ser accesibles a toda la comunidad.

4. Programas y servicios que aceleren la autonomía de los inmigrantes, proyectados y administrados bajo un diálogo suficiente con los inmigrantes.

Todas estas ideas fueron introducidas por el gobierno a sus organizaciones aliadas hasta 1989, cuando las medidas fueron revisadas por aquellas personas que criticaban el multiculturalismo (Clyne \& Jupp, 2011). Estas críticas se basaron en que las medidas que fueron tomadas, solo estaban enfocadas en los grupos étnicos, mientras muchos grupos como los aborígenes, no deseaban ser tratados como un grupo minoritario. Fue también indicado que los principios del multiculturalismo debían cubrir las necesidades de todos los grupos sociales, como el grupo de los adultos mayores, entre otros. Debido a esta revisión se establecieron tres nuevas ideas:

1. Identidad cultural

Todos los australianos tienen el derecho de expresar y compartir la tradición cultural personal, incluyendo su idioma y religión dentro los límites que fueron establecidos.

2. Justicia social

Todos los australianos tienen el derecho de ser tratados por igual y tener la misma oportunidad. Eliminar todas las barreras de razas, etnia, cultura, religión, idioma, sexo, lugar de origen, etc.

3. Rendimiento económico

La necesidad de desarrollar la utilización eficiente, el mantenimiento de las habilidades técnicas y talentos de todos los australianos sin prejuicio en sus orígenes.

Dentro de estas nuevas medidas, el gobierno también estableció limitaciones a los principios del multiculturalismo en Australia. Los tres siguientes puntos fueron afirmados;

1. Todos los australianos deben servir para el futuro de Australia, y además deben cumplir su responsabilidad en mejorar el futuro del país.

2. Todos los australianos son llamados a acceder las reglas básicas de la sociedad australiana. Estas reglas básicas vienen a ser: la dominación de la constitución y las leyes, la tolerancia e igualdad, la democracia parlamentaria, la libertad de la palabra y de religión, el inglés como la lengua oficial y la igualdad sexual. 
3. El otorgamiento de los derechos es realizado cuando se cumplen las obligaciones. El derecho de manifestar su propia cultura y principios, conllevan responsabilidad mutua, que significa aceptar los derechos a manifestar opiniones y valores de los demás.

Después de algunas modificaciones, estas medidas fueron publicadas, pero no fueron muy bien implementadas en las leyes.

En 1996, el partido liberal de Australia ganó las elecciones y continuó con los mismos principios del multiculturalismo. Debido a todos estos acontecimientos, el multiculturalismo en Australia tuvo muchos cambios que lo llevaron a ser conocido como el «multiculturalismo australiano» (Ozdowski, 2013). No obstante, en el año 2006, el secretario parlamentario del departamento de asuntos de inmigración y multiculturales, Andrew Robb, declaró que es importante unir los valores e identidad de los ciudadanos australianos para mantener una sociedad de paz (Moran, 2016, pp. 145). Esto hizo cambiar la perspectiva de la ciudadanía, y luego se elaboró un examen para que los inmigrantes que solicitaban la ciudadanía confirmarán si acaso compartían o no los valores e identidad común de la sociedad australiana. En las elecciones de 2007, el partido laborista australiano ganó el poder político y comenzó la discusión sobre el tema del multiculturalismo una vez más. Al final llegaron a una conclusión de cuatro puntos para resolver el problema del multiculturalismo:

1. Superar el problema de la diversidad de las religiones y culturas en Australia, para llegar a una unión social.

2. Superar el problema de la discriminación racial y de la falta de tolerancia.

3. Conversar con muchas más comunidades sobre lo bueno que trae la diversidad cultural a la sociedad y economía en Australia.

4. Superar los problemas que tengan que ver con la participación social y civil de los inmigrantes.

Por último, en 2017 se pudo ver que Australia siguió llevando los principios del multiculturalismo con su último slogan; 'Australia multicultural: unida, fuerte, exitosa'. Los valores que se comparten entre sus ciudadanos son; el respeto, la igualdad y la libertad (Australian Government, 2017). En esta última declaración se puede observar que Australia sigue teniendo algunos obstáculos para lograr sus objetivos, sin embargo, gracias a su discurso firme en defensa de los principios del multiculturalismo, están seguros de que podrán lograr la armonía que tanto anhelan en sus ciudadanos. 
La historia sobre la introducción y aplicación del multiculturalismo en Australia, puede decirse que describe la historia en general de Australia. Los principios del multiculturalismo no solo fueron aplicados en la educación del país, sino que también fueron tratados en el mismo sistema social, siendo varias veces modificado según las circunstancias de los problemas nacionales de la época.

\subsection{La integración: ejemplo de Francia}

A continuación, examinaremos el caso de Francia, país que vivió la revolución del siglo XVIII. Francia se vio en la necesidad de una política para la unificación de sus ciudadanos debido a la gran diversidad de culturas que coexistían en su territorio. La diferencia de las políticas del «multiculturalismo» con la «unificación» es que el multiculturalismo acepta todo tipo de diferencias y trata de mantener a sus ciudadanos de una forma equitativa. Por otro lado, la unificación de Francia busca la igualdad e integración entre todas las culturas (Clair, 2011). Para lograr esta igualdad social, el gobierno francés prohíbe todo tipo de símbolos religiosos en lugares públicos, como en los colegios, y no prioriza ningún grupo étnico por sobre otro. Entre los principios que sigue el gobierno francés, no hay ninguna ley que prohíba la religión o ideas particulares, pero sí prohíbe transmitir este tipo de pensamientos en la enseńanza pública. En la ley fundamental de Francia se ve el valor que lleva en común, «La Laïcité». La educación no es una excepción en esta ley, está escrito que la enseñanza pública debe basarse en la idea de «la República» y debe transmitir la libertad, separación, neutralidad e igualdad como valores fundamentales para ser un ciudadano francés (L'association Coexister, 2016).

Debido a estas medidas, no existió ningún tipo de ayuda especial para los hijos de inmigrantes en la enseñanza pública. Sin embargo, el Ministerio de Educación estableció "distritos de preferencia educativa» (ZEP: zones d'éducation prioritaires) en 1982, colocando a más profesores y una ayuda económica para estos colegios. En 1997, se hizo una revisión de este sistema y se creó una nueva red para facilitar la enseñanza (REP: Réseau d'éducation prioritaires). No obstante, los profesores con experiencia no deseaban ir a estos colegios porque la carga era excesiva, así que los profesores recién formados eran colocados en dichos colegios. Según García-Arjona, Arjona Garrido y Checa Olmos (2012) para atender a este problema, el gobierno en 2006, identificó a los colegios más necesitados de ayuda, nombrándolos como «Escuelas de Ambición y Éxito», creando así la red entre estos colegios llamada «Red de Ambición y Éxito» (Réseaux ambition réussite - RAR). Mayor ayuda econó- 
mica fue entregada a estos colegios para luego también colocar a profesores con más experiencia, ayudantes y enfermeras. En especial, los colegios que tenían una mayor diversidad social, fueron fusionados por una nueva red llamada RRS. Así fue como la ayuda para los colegios se fue realizando dentro de la idea de «La República».

La idea republicana en Francia tiene una larga historia, cuyo origen data de finales del siglo XIX. En este tiempo, por causa de la baja natalidad y la primera guerra mundial, la población francesa tuvo una gran caída. Por este motivo, el gobierno abrió sus puertas para los inmigrantes. Después de la segunda guerra mundial, el país pasó por una época de crecimiento económico llamada «Edad de Oro del Capitalismo». Durante este tiempo el gobierno acogió a muchos inmigrantes de España, Portugal, Magreb, etc. con la finalidad de que trabajaran en las minas y en la industria de automóviles, pero con bajos sueldos. Durante este tiempo, los inmigrantes llegaron a Francia solo por motivos laborales, por ende, la mayoría fueron hombres sin familias.

En 1973 ocurrió la primera crisis del petróleo y el siguiente año Francia cerró sus puertas para los inmigrantes. A pesar de esta medida, el número de ingresos de los inmigrantes a Francia no se detuvo. Muchos trabajadores inmigrantes llamaron a sus familias para comenzar una nueva vida en Francia. El gobierno francés permitió la inmigración de los familiares de los trabajadores por asuntos de derechos humanos. El gobierno francés trató de ayudar a los inmigrantes para regresar a sus países de origen otorgándoles 10000 francos por persona, pero el número de inmigrantes no se redujo. En lugar de reducir dicho número, el gobierno creó una ley especial para aceptar a los inmigrantes ilegales en 1981. Debido a todos estos acontecimientos, Francia se tornó en una nación diversa, racial y culturalmente. La situación parecía bajo control, hasta que sucedió el caso de una niña musulmana que utilizaba un velo para cubrir su cabeza, en 1989. Después de este acontecimiento, otros casos de discriminación contra los inmigrantes ocurrieron. En 2002, se abrió una asamblea para fortalecer las políticas republicanas. Dos años después, se legisló la ley francesa sobre la laicidad, que prohibió todo tipo de símbolos religiosos dentro de los colegios públicos. En 2005, un joven inmigrante murió electrocutado por ser perseguido por la policía. Muchos de los inmigrantes de la segunda y tercera generación se pronunciaron contra estas discriminaciones, hasta que un día el presidente Chirac reconoció oficialmente estas discriminaciones. La ley que fue establecida en 2006 propuso los siguientes cuatro puntos:

1. Control de la inmigración

2. Medidas contra el abuso de los procedimientos de inmigración 
3. Impulso a la política de la «Inmigración Escogida»

4. Impulso de una integración exitosa (Clair, 2011)

Esta nueva ley abolió la ley que legalizaba a los inmigrantes que llevaban más de diez años viviendo en Francia sin ninguna condición. Adicionalmente, esta ley destacó la inmigración escogida, solo aceptando a inmigrantes con grandes capacidades y talento, con una visa por tres años renovable.

En esta ley se hizo obligatorio "el contrato de acogida e integración», el cual incluye, el aprendizaje del idioma francés y la comprensión de la cultura social común en Francia. También es obligatorio atender cursos de educación ciudadana. A cambio de todas estas obligaciones, se brinda apoyo para encontrar trabajo y adaptarse en las escuelas.

La historia de la inmigración en Francia tiene su base en las ideas republicanas. Sin embargo, las políticas para la integración de sus ciudadanos han causado problemas y han creado discriminación entre los grupos étnicos. Un ejemplo de esto fue la reciente noticia sobre el terrorismo islamista en París. Muchos expertos argumentan que este caso es resultado de los inmigrantes de segunda y tercera generación que fueron omitidos por las políticas para los inmigrantes. La idea de la integración está basada en la igualdad de los ciudadanos, pero en realidad la igualdad no siempre es equitativa para todos los grupos étnicos y esto puede causar conflictos entre ellos.

Estas dos ideas no son las únicas entre los países que poseen grandes populaciones de inmigrantes. Sin embargo, estas dos describen perfectamente la situación en Japón. En el siguiente capítulo se verá como Japón se enfrenta al fenómeno de la globalización especialmente desde la perspectiva de la educación.

\section{LA EDUCACIÓN JAPONESA}

Japón, por ser un país insular, siempre ha tenido un método educativo particular. Hasta antes de que se estableció el sistema de enseñanza en 1872, los campesinos enviaban a sus hijos a los templos sintoístas para que aprendieran sobre la religión y también a leer, escribir y calcular. La educación siempre ha ocupado una posición importante en la historia japonesa, sin embargo la educación siempre se ha basado en los principios de asimilación, ya que Japón ha sido considerado como una nación homogénea por mucho tiempo. En tiempos de guerra, el objetivo de la educación era unificar el pensamiento de los ciudadanos para combatir a sus enemigos. Esto se puede ver reflejado en el contenido de los textos escolares de esas épocas. Después de la derrota de la 
Segunda Guerra Mundial, Japón se tornó una nación democrática y la educación se fundamentó en las medidas occidentales.

\subsection{El extranjero en la educación japonesa}

En la historia de la época moderna de Japón, se definen dos tipos de grupos de extranjeros, «Oldcomers» y «Newcomers». Estos dos grupos se diferencian, no por sus valores étnicos, sino por la época en la cual llegaron a Japón. Estos grupos han sido tratados de manera diferente por el gobierno japonés y sus formas de emigrar a Japón son totalmente diferentes. En este capítulo se describirá la diferencia de estos dos grupos, desde el punto de vista de la educación.

\subsubsection{Oldcomers}

Existen varias definiciones para distinguir los dos grupos mencionados anteriormente. En este artículo se utilizará la modificación de la ley de inmigración de 1990 para entender las diferencias que separan a estos dos grupos. A partir de esta modificación de ley, es posible dividir la política para los «Oldcomers» en cuatro partes. 1) La época de ocupación (1945-1952), 2) La época desde el tratado de San Francisco, hasta antes del tratado de Japón con la República de Corea (1952-1965). 3) La época posterior al tratado de Japón con la República de Corea hasta el memorándum de los ministros de Japón y la República de Corea (1965-1991). 4) Después del Memorándum de los ministros de Japón y la República de Corea (1991, en adelante) (Kurihara, 2010).

Durante la primera época, el gobierno japonés prohibió la formación de las llamadas «Escuelas Étnicas». Históricamente, después de la guerra, el mayor grupo étnico residente en Japón era el coreano. Durante esta época la educación era obligatoria para todos, incluyendo a los coreanos, es por esto que muchos estudiantes coreanos se dispersaron entre los colegios públicos japoneses. Sin embargo, más del $40 \%$ de los estudiantes coreanos dejaron la escuela por falta de comprensión del idioma, de las clases y de atención hacia sus necesidades básicas. En la segunda época, después del tratado de San Francisco, la nacionalidad que se les había otorgado anteriormente a los coreanos fue anulada y perdieron el derecho de recibir una educación gratuita. En el caso que los ciudadanos coreanos y de otras nacionalidades desearan recibir la educación pública japonesa, estos tendrían que pagar, exceptuando aquellos residentes extranjeros que vivían en ciudades con un gran número de inmigrantes. Después de 1965, durante la tercera época, debido al tratado de Japón con Corea, tanto el ingreso a los colegios japoneses como la adquisición de los textos escolares para los estudiantes coreanos se tornó gratuito, 
es decir tenían los mismos derechos que los alumnos japoneses. A pesar de esto, la ley dejó en claro que los alumnos coreanos debían ser tratados de la misma manera que los alumnos japoneses, haciendo entender que no habría ayuda especial para que estos aprendieran el idioma japonés. A estos alumnos coreanos, no se les tenía permitido la enseñanza de su cultura e idioma dentro del colegio. Después del memorándum firmado por los ministros de ambos países, durante la cuarta época, se decidió que la educación de los alumnos coreanos sería gratuita sin ninguna prohibición en el aprendizaje del idioma y la cultura de sus orígenes. El apoyo para el aprendizaje del japonés dentro del colegio fue autorizado a nivel nacional. Debido a ciertos precedentes de algunas ciudades con un alto número de ciudadanos extranjeros, las medidas nacionales fueron implementadas a lo largo del archipiélago nipón, incluyendo a los «Newcomers». Gradualmente, estas medidas han sido modificadas para brindarles apoyo a los Newcomers.

\subsubsection{Newcomers}

En general, se puede decir que hay tres tipos de grupos étnicos considerados como Newcomers: los de origen latinoamericano, los del sudeste asiático y los inmigrantes de China (Shimizu \& Shimizu, 2001).

Después de la revisión de la ley de inmigración japonesa, se mitigó la revisión del visado para los descendientes de japoneses hasta la tercera generación, esto atrajo a un gran número de personas residentes de países latinoamericanos, el primero grupo étnico, que poco a poco comenzaron a inmigrar a Japón, con el motivo de trabajar, juntar dinero y luego regresar a sus países para cumplir sus sueños. El segundo grupo étnico, proveniente del sudeste asiático, comenzó a ingresar a Japón en la década de 1970, durante la guerra en Vietnam. Muchos vietnamitas, laosianos y camboyanos se vieron en la necesidad de salir de sus países por problemas políticos y económicos. El gobierno japonés aceptó la entrada de inmigrantes de estos países, estableciendo algunos lugares de refugio dentro de Japón para ayudarlos a adaptarse mejor. Aparte de estos tres países, los indonesios comenzaron a inmigrar a finales de la década de 1980 con las mismas motivaciones que los latinoamericanos. El tercer grupo étnico, los inmigrantes de China, se separaron en dos grupos. El primer grupo apareció durante la guerra, como obreros junto con los coreanos, este grupo de chinos pudieron conservar sus valores culturales y son conocidos como «Oldcomers». El segundo grupo de chinos, llamados «Newcomers» inmigraron a Japón por motivos de trabajo como los otros dos grupos de «Newcomers». 
En un comienzo, todos los grupos de «Newcomers» fueron tratados como «extranjeros que no hablaban el japonés». Esta forma de ver a los extranjeros también fue reconocida en los colegios. Los alumnos extranjeros no eran identificados por sus países de origen, sino porque no sabían japonés y porque no podían seguir con el ritmo de las clases. Como se ha mencionado anteriormente, la educación para los alumnos extranjeros ya no era obligatoria, y si elegían recibir la educación japonesa, estos iban a ser tratados por igual.

El problema más grande que tuvo que enfrentar la escuela japonesa estuvo relacionado con la inestabilidad de los «Newcomers». Una vez que los niños se adaptaban a las escuelas, ellos se mudaban por causa del trabajo de los padres. Así fue como el apoyo de los colegios se tornó en una ayuda temporal, solo para que los alumnos aprendieran un japonés básico sin tener en mente el futuro del alumno. El Ministerio de Educación, Cultura, Deporte, Ciencia y Tecnología (MEXT) japonés, comenzó una investigación en 1991 para comprender la situación de los alumnos extranjeros en los colegios japoneses (MEXT, 2011). De acuerdo a esta investigación, se pudo observar que el problema u obstáculo más grande que tienen los estudiantes extranjeros es el idioma.

\subsection{La educación japonesa para los ciudadanos extranjeros}

Según se ha visto en la historia de ambos grupos de extranjeros, Japón se puede definir como una nación multicultural. Comparando con los países occidentales, el porcentaje en relación con la población general es inferior. Sin embargo, en las ciudades en las que residen más extranjeros, el problema con el lenguaje y los estudios, está siendo bastante grave y requiere de una nueva política que ayude a estos alumnos para que puedan conseguir la oportunidad de recibir una educación de calidad que les ayude a cumplir con sus metas académicas al igual que cualquier alumno japonés.

En el siguiente apartado nos enfocaremos en cómo el gobierno está atendiendo las necesidades de los niños para ver en qué puede mejorar y luego ofrecerles una mejor educación a estos alumnos de diversos orígenes.

\subsubsection{La idea detrás de la educación para los niños extranjeros}

Como se ha mencionado en el capítulo anterior, el gobierno japonés se ha centrado principalmente en el problema del idioma de los niños extranjeros que asisten a las escuelas públicas. El gobierno comenzó colocando profesores extras para la enseńanza del idioma japonés en los colegios. La metodología de estos profesores se basaba en solo los primeros pasos del aprendizaje del idioma y no se centraban en el japonés para el uso en los estudios. 
En 2003, se publicó el currículo de JSL (Aprendizaje del Japonés como segunda lengua) estructurado para niños que no hablan el japonés como primera lengua, enseñándoles el idioma y las materias al mismo tiempo (MEXT, 2011). Todos estos esfuerzos fueron para que los niños extranjeros aprendieran el japonés y se adaptaran a los colegios públicos. Es decir, el gobierno bajo sus políticas para el aprendizaje del idioma japonés tiene la idea de asimilar a los niños extranjeros al sistema japonés.

En Japón, la educación pública de primaria y secundaria son obligatorias y gratuitas para todos sus ciudadanos. Sin embargo, para los ciudadanos extranjeros no son obligatorias y es por eso que los que desean ingresar a los colegios japoneses tienen que hacer una solicitud a las municipalidades. Hasta el año 2006, los alumnos extranjeros eran tratados y vistos solo como estudiantes temporales, puesto que estos pensaban que en algún futuro cercano regresarían a sus países de origen. Ese año, MEXT anunció oficialmente a todos los colegios públicos, que los estudiantes extranjeros serían reconocidos como estudiantes establecidos ya que la mayoría de ellos terminaban graduándose en Japón, no regresaban a sus países de origen y comenzaban sus estudios en escuelas superiores e incluso comenzaban a trabajar (MEXT, 2006).

Los colegios se vieron en apuros porque faltaba recurso humano que pudieran atender a estos niños. En las regiones en las que vive un mayor número de extranjeros, existen ONG que ayudaban a los niños en su aprendizaje del japonés y otras materias. Estas ONG siguen una determinada metodología de cómo enseñar a estos nińos, y los colegios comenzaron a acudir a ellos. Sin embargo, muchas de estas organizaciones están muy limitadas del recurso humano y económico. Así el gobierno comenzó a hacer proyectos con las ONG, entregándoles ayuda económica. Una de las desventajas de estos proyectos es que son temporales, y por ende no se pueden planear a largo plazo. En 2008, MEXT publicó el Gaikokujin Jido-Seito Ukeire no Tebiki (Manual para recibir a estudiantes extranjeros), en este manual se pueden encontrar descripciones detalladas acerca de los problemas que los niños sufren y maneras en las cuales pueden ayudarlos. Asimismo, se describe la forma en cómo los colegios pueden colaborar con las ONG regionales. Al comienzo de este manual, está escrita la idea del recibimiento a los niños extranjeros, y en esa parte se puede ver reflejada la intención del gobierno de querer aceptar las culturas e idiomas de los nińos, no obstante, el real motivo de esta ayuda es para que estos niños se adapten a los colegios japoneses, siguiendo las reglas y sistema japonés. Quiere decir que estos niños son aceptados como son, con sus culturas, idiomas, etc., y que están bajo los principios del multiculturalismo. Además, dentro del currículo de las escuelas públicas también está incorporada la educación sobre 
el entendimiento internacional, y dentro de estas clases muchas veces se habla sobre los países de los estudiantes extranjeros que atienden a estos colegios para que los estudiantes japoneses tengan un mejor entendimiento sobre la cultura e idioma de estos. Sin embargo, los estudiantes extranjeros siempre son evaluados como los otros estudiantes japoneses, y en muchos casos estas evaluaciones llegan a ser injustas. Como resultado, los estudiantes extranjeros son reconocidos como estudiantes con bajo rendimiento y en algunos casos con mala conducta, lo que afecta directamente a sus probabilidades de seguir con sus estudios en escuelas superiores. En consecuencia, el porcentaje de estudiantes extranjeros que siguen sus estudios en la secundaria superior, es de tan solo el 56\%, mientras más del 90\% de los japoneses continúan.

Esta contradicción que está pasando en los colegios afecta mucho a la enseñanza de los profesores. Asimismo, los estudiantes cuando llegan hasta un punto que ven que no tienen posibilidades para seguir sus estudios, ven afectada su autoestima, quedan rezagados en los estudios, y pierden las posibilidades y el acceso para seguir sus estudios y tener así, una mejor vida que sus padres, los cuales en muchos casos, trabajan como obreros en fábricas.

\subsubsection{Sistema sostenible para la ayuda de los alumnos con diversos fondos}

El resultado de los problemas educativos de los niños extranjeros que tiene Japón no solo afecta al mismo país, sino que también afecta a los países de origen de estos niños. Actualmente se está viendo que los nińos regresan con sus familiares a sus países de origen. Sin embargo, muchos de ellos han perdido sus idiomas nativos o nunca lo adquirieron por haber nacido en Japón. Se puede decir que estos nińos tienen menos posibilidades de surgir en sus países de origen que en Japón por problemas del idioma y costumbres. Sus países de origen se están tornando en lugares desconocidos. Esto es lo que está causando el problema de la asimilación en la educación japonesa.

Lamentablemente para estos nińos, dentro de las políticas educaticas se puede ver que el gobierno japonés solo se preocupa por los niños que están actualmente asistiendo a los colegios públicos, pero una vez que se apartan o gradúan de los colegios, desaparecen totalmente de los ojos de las políticas.

Las políticas para los niños ciudadanos extranjeros necesitan ser más inclusivas desde que nacen hasta que se gradúen de las escuelas y obtengan un trabajo. Ahora que todavía el número de extranjeros viviendo en Japón es bajo comparado con otros países económicamente desarrollados, se tienen que tomar las medidas necesarias, ya que el mundo se está globalizando y no falta mucho para que el porcentaje de inmigrantes aumente y los problemas empeoren. 
También se están viendo nuevas medidas tomadas por los mismos medios educativos. Las universidades, incluyendo algunas nacionales, están abriendo sus puertas a los estudiantes extranjeros, agregando una nueva forma de evaluación. Esta no solo se basa en los puntajes de los exámenes de los alumnos, sino que toman en cuenta las motivaciones y otras habilidades que no pueden ser evaluadas en los exámenes académicos actuales (Utsunomiya University, 2016). A pesar de que ha habido avances con respecto al tema, también han surgido varias opiniones que critican estos cambios, ya que son consideradas como medidas de discriminación inversa, puesto que esto significa que solo los extranjeros tienen la posibilidad de ingresar a buenas universidades sin dar un examen, mientras que los demás están obligados a darlos. Es por eso que el gobierno debe establecer nuevas y mejores políticas que regulen esta situación lo antes posible para que la sociedad conozca y entienda la delicada realidad de estos estudiantes.

No solo el mundo de la educación está viendo con atención cómo el gobierno manejará sus políticas con los ciudadanos extranjeros de ahora en adelante, sino que en todos los sectores se está analizando cómo pueden tratar a sus trabajadores, pacientes y clientes extranjeros. Esta mentalidad de separar a los japoneses de los extranjeros fue planteada por las políticas y la historia japonesa, pero la creencia de que Japón es una nación homogénea ya es historia. La clave para que estos nińos sean criados como buenos ciudadanos, está en la mentalidad de los mismos japoneses y en sus políticas.

\section{Conclusiones}

En la era de la globalización se ha tornado una dificultad para las naciones definir «quién" es su pueblo. Este mismo problema se puede ver por las políticas de los países discutidos en este artículo. El objetivo de estas políticas se basa en la «unidad del pueblo». Sin embargo se puede ver que estos tres países han tomado diferentes métodos para hacerlo. Los métodos se deben a la historia de los países como se ha mencionado dentro del artículo. Francia empezó a cambiar sus políticas debido a la diversidad de grupos étnicos en el siglo XVIII, mientras Australia fue tarde en el siglo XX, no solo con el objetivo de "la unión del pueblo», sino también con motivos del crecimiento económico del país. El crecimiento de la población extranjera en Japón está siendo notable y se están necesitando nuevas medidas y políticas para definir quién es «el pueblo». Hasta ahora, "el pueblo» son los ciudadanos con nacionalidad japonesa. Sin embargo, dentro de los ciudadanos extranjeros (ciudadanos que no tienen la nacionalidad japonesa) hay personas que nunca han ido a sus 
países de origen (nacidos de padres extranjeros en Japón) o ya no tienen donde regresar por haber traído toda su familia a Japón. Lamentablemente, Japón no tiene políticas concretas para estos ciudadanos y son ONG las que están actuando para proteger sus derechos y vidas. Ultimamente se está discutiendo en el parlamento sobre la baja natalidad y envejecimiento de la población japonesa. Dentro de una de las soluciones está la introducción del trabajador extranjero para el servicio de la asistencia pública. Sin ninguna política que se refiera a la vida de estos nuevos extranjeros, se causará el mismo conflicto que ocurrió después de la década de 1990 cuando los latinoamericanos y surasiáticos entraron al país. Por eso es urgente que Japón demuestre su posición al respecto de cómo van a definir a «su pueblo» a través de sus políticas.

En el presente artículo se pudo ver cómo Australia y Francia desarrollaron ciertas políticas para los inmigrantes, dos países que se puede decir que representan los principios del multiculturalismo y la integración civil. Ambos tienen puntos débiles y siguen enfrentando muchos problemas, pero con principios concretos bajo sus políticas ayuda a mantener a sus ciudadanos en armonía. Por otro lado, Japón hasta ahora no tiene unos principios planteados en sus políticas y no se puede apreciar con claridad la posición del gobierno. Dentro del sistema educativo, se respetan los valores de cada uno de los estudiantes y se les enseńa que es importante tener originalidad y demostrar su personalidad, pero una vez que terminan sus estudios en el colegio, lo que les dice la sociedad es «asimilarse» al sistema actual. Estas contradicciones son causadas por las mismas políticas, así que una unificación de principios en las políticas del país es urgentemente necesaria.

Los niños con raíces extranjeras son tratados aún como ciudadanos temporales y no permanentes, es por eso que los nińos son bienvenidos en las escuelas durante la educación obligatoria, pero estos deben adaptarse rápidamente al entorno, asimilándose a los japoneses para luego poder tener una mejor vida después de graduarse, sino no son bien recibidos en las empresas y en la sociedad japonesa.

Este artículo no discutió sobre cuáles serían los principios ideales para Japón, pero se concluye con la necesidad de definir unos principios para poder ayudar a estos estudiantes extranjeros y su vez convertir a Japón en una sociedad más abierta para la comunidad internacional. 


\section{REFERENCIAS BIBLIOGRÁFICAS}

Australian Bureau of Statistics (2016a). Migration, Australia, 2015-16. Referencia en: http://www.abs.gov.au/AUSSTATS/abs@.nsf/mf/3412.0

Australian Bureau of Statistics (2016b). Loi du 9 décembre 1905 concernant la séparation des Eglises et de l'Etat. Referencia en: https://www.legifrance. gouv.fr/affichTexte.do?cidTexte=LEGITEXT000006070169\&dateT exte $=20171210$

Australian Government, Department of Immigration and Border Protection (s.f.). Abolition of the "White Australia» Policy. Referencia en: http:// www.border.gov.au/about/corporate/information/fact-sheets/08abolition

Banks, J. A. (2006). Improving Race Relations in Schools: From Theory and Research to Practice. The Journal of Social Issues, 62(3), 607-614. https:// doi.org/10.1111/j.1540-4560.2006.00476.x

Bedmar V. L., Terrón Caro M. T. (2013). Políticas socioeducativas de integración de los inmigrantes en Alemania, España y Francia. Pedagogía Social. 3ra época, 21, 111-139.

CLAIR (2011). Australia no tabunka shugui seisaku (Las políticas bajos la doctrina del multiculturalismo en Australia). Sidney, Australia: Clair Report No. 358.

CLAIR (2011). Furansu no imin seisaku: Imin no shutsunyu kanri gyousei kara shakai tougou seisaku made (Las políticas de inmigración de Francia: desde los asuntos administrativos de inmigración hasta las políticas de la integración social). París, Francia: Clair Report No. 363.

Clyne, M. y Jupp, J. (eds.) (2011). Multiculturalism and integration: A Harmonious Relationship. Canberra, Australia: ANU ePress. https://doi.org/10.26530/ OAPEN_459378

Galbally, F. (1978). Migrant Service and Programs- Summary. Referencia en: http://www.multiculturalaustralia.edu.au/doc/galbally_1.pdf

García Castaño, F. J., Pulido Moyano, R. A. y Montes del Castillo, A. (1997). La educación multicultural y el concepto de cultura. Revista Iberoamericana de Educación, 13.

García-Arjona, N., Arjona Garrido, Á. y Checa Olmos, J. C. (2012). Aproximación etnográfica al estudio de relaciones interétnicas en educación física. Estudios de caso en Francia y España. Gazeta de Antropología, 28(1), artículo 05. Referencia en: http://hdl.handle.net/10481/19921

Gay, G. (1983). Multiethnic education: Historical developments and future prospects. Phi Delta Kappa, 64, 560-563. 
Kurihara, M. (2010). Oldcomer no kodomo wo taisho to suru kyouiku seisaku ni kan suru rekishi teki kousatsu: Osaka shi kyouiku Iinkai wo jirei toshite (Estudio histórico sobre las políticas educativas enfocadas en los niños de oldcomers: Ejemplo del comité educativo de la prefectura de Osaka). Boletín del Departamento de Educación de la Universidad de Waseda, 17(2), 181-190.

L'association Coexister (2016). La laïcité en trois minutes (ou presque). Referencia en: http://www.gouvernement.fr/qu-est-ce-que-la-laicite

Legifrance (2015). Loi du 9 décembre 1905. Referencia en: https://www.legifrance.gouv.fr/affich Texte.do?cidTexte=LEGITEXT000006070169\&date Texte $=20171210$

MEXT (2001). Gakkou kyouiku ni okeru JSL karikyuramu no kaihatsu ni tsuite (Desarrollo del currículo para JSL en la educación colegial). Recuperado de http://www.mext.go.jp/a_menu/shotou/clarinet/003/001/008/020. htm

MEXT (2006). Gaikokujin jido seito kyouiku no juujitsu nituite (Reforzamiento de la educación para los estudiantes extranjeros). Referencia en: http:// www.mext.go.jp/a_menu/shotou/clarinet/004/002/001.pdf

MEXT (2011). Gaikokujin jido seito ukeire no tebiki (Guía para la recibir a los estudiantes extranjeros). Referencia en: http://www.mext.go.jp/a_menu/ shotou/clarinet/002/1304668.htm

Moran, Anthony (2016). Enduring in Practice if Not in Name? - Official Multiculturalism During and Beyond the Howard Government. En A. Moran (ed.), The Public Life of Australian Multiculturalism: Building a Diverse Nation (pp. 109-167). Cham, Switzerland: Springer.

Ozdowski, S. (2013). Australian Multiculturalism: The Roots of its Success. En K. Mazur, P. Musiewicz, y B. Szlachta (eds.), Promoting Changes in Times of Transition and Crisis: Reflections on Human Rights Education. https://doi. org/10.12797/9788376383651.10

Shimizu, K., Shimizu, M. (2001). Newcomer to kyouiku: Gakko bunka to Ethnicity no katto wo megutte (La educación de los Newcomers: Recorriendo el conflicto entre la cultura escolar y la característica étnica). Tokio, Japón: Editorial Akashi.

Stanford University Center for the Study of Language and Information (CSLI) (2006). The Stanford Encyclopedia of Philosophy. Referencia en: https:// plato.stanford.edu/entries/republicanism/

Utsunomiya University (2016). DEAR News, 175. 